\title{
Sterilisation and intellectually disabled people in New Zealand—still on the agenda?
}

\author{
C Hamilton* \\ University of Waikato, Hamilton, New Zealand \\ (Received 7 September 2011; accepted 24 August 2012)
}

\begin{abstract}
Support through care and protection within a medical framework, rather than through the idea of independence within the least restrictive environment, continues to guide service provision for intellectually disabled people in the sexuality area. Past practices have included use of involuntary sterilisation. This article outlines the outcome of a search for information undertaken because of concerns that use of sterilisation-related procedures may remain embedded in contemporary approaches to sexuality support management. Verified instances of hysterectomy carried out between 1991 and 2001 were uncovered. Documents tabled at a Parliamentary Select Committee in 2003 expressing concerns about use in relation to young disabled girls were also found. Requests for sterilisation-related procedures exemplify how the right of all vulnerable citizens to full bodily integrity is currently adjudicated in New Zealand. It is suggested that further research is needed to pinpoint and address the underlying social customs through which requests for such procedures are negotiated and resolved.
\end{abstract}

Keywords: intellectual disability; sexuality; sterilisation; rights; gender

\section{Introduction}

The legacy of the eugenics movement in a variety of Commonwealth and European countries has been investigated through a number of research initiatives completed in the last decade (e.g. Snyder \& Mitchell 2001; Malacrida 2006; Living Archives 2010). These accounts affirm that involuntary sterilisation of numbers of intellectually disabled people took place in the past (Tilley et al. 2012). In the case of young intellectually disabled women and girls in particular, individual case study evidence suggests that sterilisation-related procedures continue to be sought, despite a considerable tightening up of legal requirements in this area in many jurisdictions (Bersanti 2008; Hamilton 2011). Contemporary procedures are now undertaken within the framework of requests for a clinical response to problems associated with menstrual pain and distress, and as an adjunct to the management of bodily hygiene (Stansfield et al. 2007). However, they can also be sought as a way of managing sexuality and reproductive capacity (e.g. Roets et al. 2006), raising concerns that procedures requested ostensibly for therapeutic purposes may mask the presence of non-therapeutic reasons in certain cases. Nontherapeutic reasons identified in the international literature have been found to include: parent/caregiver convenience; elimination of possible genetic transmission of disabling medical conditions; averting the consequences of sexual abuse (O'Neill 1996); and fear of the financial cost to families of having to care for an unplanned child (Chu \& Lu 2011). However, because of the absence of empirical research in what is still an extremely sensitive area of investigation, the extent of contemporary requests for sterilisation-related procedures remains very unclear (Tilley et al. 2012).

\footnotetext{
*Email: hamiltca@waikato.ac.nz 
While the rhetoric of the eugenics movement was influential in the first half of the twentieth century in New Zealand (Stace 2008), practices in this country fell short of the largescale clinical programs initiated by some other euro-western nations to actively limit the reproductive capacity of those deemed 'unfit to reproduce' (Alvares et al. 2011, p. 9). Reproductive limitation by default, including segregated living for 'incurables' such as severely physically and cognitively impaired people, was widespread and continued until at least the late 1970s (Sullivan 1995). 'Care' options in these settings included sterilisation of at least some intellectually disabled people (Report of the Confidential Forum for Former In-Patients of Psychiatric Hospitals 2007; Stace 2008). However, details of such procedures were kept in institutional and clinical records; documents that remain largely inaccessible to a lay readership. As a result it is difficult to answer the question: how widespread was use of this procedure in the past, and thus to assess to what extent the legacy of this practice remains embedded in contemporary approaches to disability and sexuality support in this country. This question is important as it not clear to what extent the effects of past eugenics-related policies and practices continue to impact on the contemporary life choices and chances of intellectually disabled people in the area of sexuality and relationships.

This article explores this question against a backdrop of the recognition that the fundamental cause of disabled people's isolation and exclusion from full participation in the economic, social and political life of society has been society itself rather than the (impaired) condition of the person themselves. In this regard, the New Zealand Disability Strategy (NZDS; Office of Disability Issues 2001) and New Zealand's recent ratification of the United Nations Convention on the Rights of Persons with Disabilities (United Nations 2007) in 2007 provide tangible evidence of the strong political will to tackle the deep-seated problem of changing oppressive societal attitudes towards disabled people by facilitating the inclusion of all disabled people in local communities as full citizens with rights (Stace \& Sullivan 2011). Yet, as Stace and Sullivan (2011) also point out, while political recognition of the need to remove social barriers is now well substantiated, provision of services and support at local community level remains tied into the idea of disabled people as "deficit, "other" and, in extreme circumstances, as "non-people to be locked away" (Stace \& Sullivan 2011, p. 52). Within this binary, contemporary developments in thinking about the function of the individual (disabled) body as a positive locus of social power are set against wider representations of bodily norms that drive the constituting power of social organisation in the area of disability and sexuality. This point is briefly expanded on at the end of the paper.

An initial exploration of the legal position in 2010 surrounding contemporary use of this process found that it is possible for a sterilisation-related procedure to be initiated in relation to a young intellectually disabled person outside of any independent judicial scrutiny (Shrenk 2011). The Protection of Personal and Property Rights Act 1988 safeguards the interests of intellectually disabled adults who are 18 years old and over, in that any application regarding intellectually disabled people in this group must be processed through the Family Court. In consideration of intellectually disabled minors, however, court authorisation is not required. The Care of Children Act 2004 (COCA) confers on the child's guardians, together with appropriate medical professionals, the authority to decide which kind of medical treatment, including hysterectomy, intellectually disabled minors under the age of 16 will receive. In the case of 16 and 17 year olds with an intellectual disability a substantive grey area exists, in that obtaining a Family Court order for a sterilisation-related procedure is not legally necessary. When a procedure is sought for an individual in this age group, the views of the parents/guardians will be taken into account. However, it is up to the health provider 
to form an independent decision about the young person's ability to provide consent for this process (see Shrenk 2011 for an extended discussion of legal issues related to the consent process).

This paper details a follow-up investigation of incidence and prevalence of contemporary sterilisation-related procedures and reasons for use of this procedure in New Zealand, undertaken in view of the legal circumstances noted above. The lack of judicial protection for at least some young intellectually disabled people's sexual and reproductive future raises a number of ethical questions. How accurate can clinical assessments be about the future life chances of a young person with severe physical and/or cognitive impairment? Should those who have the greatest input into the care of a young disabled family member have the greatest say in life-changing decisions about the treatment of that person? Why is it assumed that able-bodied people (i.e. those who are not informed by 'the lived experience of disability'; Kittay 2011, p. 615), are best qualified to adjudicate the future needs, desires and interests of a (young) disabled person - especially a person who cannot easily communicate their own point of view? Without access to information about how all aspects of the (sexual) health and wellbeing of young intellectually disabled people are currently handled, the issues these questions raise cannot be fully explored.

\section{Incidence and prevalence data}

Under Section 8(1) of the Contraception, Sterilisation and Abortion Act 1977 (CSA), medical practitioners are compelled to provide a report to the Director General of Health about every sterilisation performed, including the reasons for the operation and the age of the patient concerned (Shrenk 2011). Although CSA should provide a source of accountability for sterilisation procedures performed, reports provided by medical practitioners to the Ministry of Health $(\mathrm{MOH})$ are received as hard copies and are only required when sterilisation is the primary purpose or intent of the procedure. Reports do not include any procedures performed for other-than-sterilisation medical reasons. Furthermore, they are not currently audited for accuracy or completeness. Subsets of the report information are loaded onto spreadsheets. However, these figures do not include reasons for the operation, nor do they necessarily include whether the individual concerned has an intellectual disability. Finally, report information is more readily available for publicly funded sterilisations, albeit limited to procedures requiring a hospital admission. It is not mandatory to notify the Director General of Health about privately funded procedures, nor for procedures performed in outpatient settings (J. Perrott, MOH, pers. comm. 2011). Given international findings, that hysterectomy performed on young intellectually disabled girls and women are now carried out primarily for reasons of menstrual management, obtaining figures from this source cannot provide substantive proof of this contention in this country. However, two data sources, both relating to completed procedures give some indication of the extent to which this procedure was used in New Zealand in the past. Table 1, obtained from an unpublished paper, lists numbers of sterilisation procedures performed on young people with intellectual disability age 20 and under in New Zealand between 1991 and 1994 (Gates 2000).

Table 2 lists the outcome of a nationwide database search of public hospital discharges related to hysterectomies performed on intellectually disabled young women and girls under 20 years old between August 1997 and July 2000. These were obtained from a $\mathrm{MOH}$ report initiated by the Hon. Ruth Dyson in 2000 (Wicks 2003). A review of discharge records identified 24 intellectually disabled patients who had undergone hysterectomy, with 16 operations undertaken for reasons of menstrual control.

Both datasets are manifestly far from definitive and neither represents information gathered after 2000. However, they provide an indication 
Table 1 Public and private hospital sterilisation statistics 1991-1994.

\begin{tabular}{lccccc}
\hline Operations (20 years and under) & Total & $\begin{array}{l}\text { Female } \\
<15 \text { yrs }\end{array}$ & $\begin{array}{c}\text { Female } \\
>15 \text { yrs }\end{array}$ & $\begin{array}{c}\text { Male } \\
<15 \text { yrs }\end{array}$ & $\begin{array}{c}\text { Male } \\
>15 \text { yrs }\end{array}$ \\
\hline 1991 & 54 & unknown & unknown & unknown & unknown \\
1992 & 36 & 4 & 32 & 1 & 2 \\
1993 & 38 & 26 & 10 & 1 & 1 \\
1994 & 49 & 10 & 36 & 3 & 0 \\
& 169 & & & & \\
\hline
\end{tabular}

Source: Gates 2000.

of the possible impact of legislation and policy changes in this area between 1991 and 2000, in that both sets of figures show a marked decline in use of sterilisation procedures - from 54 in a single year, 1991, to an average of eight per year nine years later. In 1991, under Section 25(3) of the Guardianship Act 1968, parents/guardians were able to give consent to medical treatment to young girls and women under the age of 18, in cases where individuals were unable to give their own consent (Shrenk 2011). Implementation of new laws and policies relating to the rights of children and disabled people in the 1990s, including the Health and Disability Commission Act 1994 and the Code of Rights 1996, may have presented a challenge to the authority of parents held under Section 25(3) of the Act. Further it was noted at the time that existing legal and policy measures could not adequately guarantee the rights of members of this group with regard to use of non-therapeutic sterilisation procedures (Thomas 1997). In relation to this caveat, Thomas (1997) recommended that additional legislative safeguards for the person concerned and their medical advisers be initiated, including consent of the court in all cases, and that an independent adviser who could act on behalf of the intellectually disabled young person concerned be appointed. Such a recommendation, plus the policy changes outlined, may have influenced clinical decisions to endorse fewer procedures by the late 1990s. Finally, the 19911994 figures detailed procedures carried out in private and public hospitals, while the 19972000 figures only included procedures carried out in public hospitals. Perhaps due to policy initiatives, more sterilisation procedures were subsequently carried out in private hospital settings.

Subsequent searches for reliable sources of data related to use of sterilisation procedures in New Zealand beyond 2000 have produced no further figures. However, a significant source of material pointing to a degree of concern in some areas about non-therapeutic use of this procedure provided a final avenue of exploration. During a parliamentary debate on the Care Of Children Bill in 2004, the Hon. Metiria Turei was noted in Hansard as urging that a section be added to the Bill that would protect intellectually disabled young women and girls from involuntary, non-therapeutic sterilisations (Shrenk 2011). In her argument, Ms Turei stated that: '[t]he fact is that sterilisation

Table 2 Public hospital discharge statistics 1997-2000.

\begin{tabular}{lccccc}
\hline Operations (<20 years) & Total & Female & Male & $\begin{array}{c}\text { Reason Genital } \\
\text { abnormalities/Cancer }\end{array}$ & $\begin{array}{c}\text { Reason Control } \\
\text { of Bleeding }\end{array}$ \\
\hline August 1997 to July 2000 & 24 & $\begin{array}{l}\text { Average Age } \\
\text { 15ys 7mths }\end{array}$ & $\begin{array}{c}\text { Age Not } \\
\text { Recorded }\end{array}$ & 8 & 16 \\
\hline
\end{tabular}


of young disabled girls is occurring in this country on non-medical grounds without their informed consent'. She also stated that reasons for use of the procedure were multiple and included family members being unsure about how to manage issues that arose when their intellectually disabled daughter started her period. In correspondence, she suggested that public submissions made to a Justice and Electoral Select Committee (J\&ESC) in 2003 and 2004 may provide some useful information (M. Turei, pers. comm. 2011). The second part of this paper provides a detailed examination of material from this source. ${ }^{1}$

\section{The Justice and Electoral Select Committee}

The J\&ESC was set up to adjudicate public submissions to the legislative changes proposed by the Care of Children Bill. Changes proposed in the Bill were of considerable public interest and a number of submissions were made, including submissions tabled by CCS and IHC. $^{2}$ Both submissions drew the J\&ESC's attention to the lack of recognition in the Bill of specific issues impacting on the health and wellbeing of disabled children. However, the CCS submission also included the areas of sterilisation and the receipt of appropriate health care' (CCS 2003, p. 5). CCS's assertion, that 'sterilisation is a practice that would not be contemplated for non-disabled children or boys' (CCS 2003, p. 5) suggests that, in 2003, this organisation was particularly concerned about the ongoing lack of legal protection for young girls and women from possible nontherapeutic use of sterilisation procedures. Concern was so strong that CCS recommended the insertion of a safeguard clause in the Bill, as follows:

38. Inability to give informed consent to sterilization

a) if a child is unable, through age or impairment, to give informed consent to sterilization a registered health professional appropriately qualified to carry out such an operation, must apply to the family court with supporting information from a second appropriately qualified health professional that the procedure is a medical necessity: and

b) the family court is to ensure the provision of a lawyer to advocate for the rights and best interests of the child. (CCS 2003, p. 6)

The J\&ESC asked CCS to provide supplementary information relating to the clause proposed. The supplementary submission tabled by CCS in 2004 included two New Zealand articles, an Australian report and a summary of two New Zealand High Court judgments related to the outcome of sterilisation procedures adjudicated before 2000 (CCS 2004). It also included a letter from the Disabled People's Assembly (DPA). This letter provided further endorsement of the content of the original CCS submission, offering 'strong support for the comments around non-consensual sterilisation of children with intellectual impairments' (Wicks 2003, p. 1).

At the request of CCS, DPA also sent supplementary information to the J\&ESC. This included a $\mathrm{MOH}$ report entitled 'Hysterectomies in young women with intellectual disabilities', dated 20 March 2002. The report was provided as an update for the then Associate Minister of Health, Hon. Ruth Dyson, from the Deputy Director General of the Disability Issues Directorate on 'work commenced since 2000 concerning the sterilisation of young women with intellectual disabilities' (Wicks 2003 , p. 2). This information included a clinical review of indications for hysterectomy in intellectually disabled young girls and women made by 'an independent expert' (Wicks 2003, p. 1), initiated at the time of the drafting of the NZDS in 2000. The results of this review were included in the $\mathrm{MOH}$ report as Appendix A. Drawing heavily on the content of Appendix A, the $\mathrm{MOH}$ report concluded that: 'the primary intention [of use of sterilisation] is the control of excessive and frequent menstruation with hysterectomy being a treatment of last resort' (Wicks 2003, p. 5). However, a close examination of the information contained in Appendix 
A raises significant doubts about the validity of this conclusion.

\section{A clinical review of indications for hysterectomy}

Appendix A consists of a two page, seven bullet point review of information from the case files of 14 of the 16 cases of hysterectomy of young girls and women performed for control of bleeding featuring in the Hospital Discharge Statistics 1997-2000 noted above (Wicks 2003, Appendix A pp. 1-2). The first point lists the average age of the 14 young intellectually disabled girls and women who had undergone hysterectomy as 15 years 7 months, with ages ranging from 13 years 5 months to 20 years 7 months. No comment is made about the absence of any clinical data in respect of cases 15 and 16. Point 2 outlines the length of time between first onset of menstruation and hysterectomy for the cases reviewed-recorded as between 1 and 7 years, although the expert also stated, somewhat cryptically, that:

Note: menarche not recorded in small number of cases so estimated it at 13 years 6 months and this is a very conservative estimate when compared with the cases where it is recorded.

This remark suggests that some procedures may have been authorised before a menstrual cycle had begun, challenging the assertion that a diagnosis of excessive bleeding could be used as the primary reason for initiating sterilisation procedures in all cases. Under Point 3: 'Patient able to participate in decision/consent process', 12 of the girls and young women are noted as being 'unable to participate in a decision/ consent process' with one judged as having a 'limited-to-reasonable ability' to decide/consent and one having 'limited' ability. No indication of the process used to ascertain ability level is included or how the issue of consent was managed for the person considered of 'limited-to-reasonable' ability. Under Point 4: 'Indication', clinical reasons for hysterectomy are outlined. Comments made by the expert under this point are reproduced in full below:

1) Management of menstruation with underlying pathology/malfunction

- in my opinion we could argue that all fit into this category

- For 14 out of 14 the prime indication is management of menstruation

- In 12 out of 14 cases menorrhagia or dysfunctional uterine bleeding is stated as the underlying pathology/malfunction which makes the management of menstruation so difficult. In the 13 case, there is incontinence of urine and faeces and whilst this is not a uterine malfunction (bold included) it is surely never the less a malfunction. In the 14th case, the girl's epilepsy is exacerbated during menstruation with an increase in the number and severity of fits and again this is surely a malfunction.

2) Management of menstruation alone

- If we don't accept the 13th and 14th cases above, then they would fit here

3) Management of menstruation and contraception

- In one case, contraception was seen as a necessary secondary indication

- In two cases, contraception is mentioned but very much as a secondary indication which would or might be useful rather than something that was necessary

- In the remain 11 cases, contraception was not mentioned

4) Contraception alone

- None

Despite knowledge that menstrual difficulties are more likely than not to present problems at some stage for all women who menstruate, and particularly for young women starting their cycle, how 'dysfunction' in any of the cases is initially clarified is not stated. While it can be said that clinical expertise covers this issue, the phrase 'it is surely a malfunction' suggests the expert herself may have wanted more information for consideration in at least some of the cases.

Point 5 indicates whether prior consideration of the decision to perform a hysterectomy was made by a clinical audit team. Eleven of the 14 cases are noted as having included the concurrence of a clinical audit committee of 
more than two medical practitioners. It was not clear to the expert whether the final three cases had been given this consideration, and two points pertaining to these cases were noted by the experts as follows:

- In two cases it is unclear whether more than the operating surgeon and GP were involved but in one of these, other cases from the same area with the same surgeon did have a multidisciplinary consideration.

- In one case only the GP and operating gynaecologist were involved - this was in an area where there is probably only one such specialist in the area.

Remarks in this area show that some procedures were sanctioned with what was considered by 1997 to be below minimum prior clinical input. Point 6 covers prior use of contraceptive procedures in each case. Prior trials of either contraceptives and/or less invasive surgery is noted in 12 of the 14 cases. In the 13th case the expert notes that no prior trial was attempted and in the 14th no prior trial of contraceptive or surgical procedure was included in the case notes. In the latter case, the reason for the lack of trial is recorded as:

... the mother was strongly opposed. She had a lot of contact with other intellectually disabled girls and was aware of the side effects and this resulted in her very strong feelings in the matter. (one of the 9 cases above more than doubled her weight on depo provera - not desirable from caregivers perspective and many of these cases have severe physical as well as intellectual disabilities).

Here, the primary reason given for no prior trial of any alternative contraceptive measureweight management - clearly does not equate to hysterectomy as the contraceptive practice of 'last resort'. In addition, this statement suggests that the parent's opinion may have significantly influenced a decision to sterilise in this case. Under Point 7: 'Able to provide personal hygiene care for self and change sanitary protection', the following brief statement is made:
In only one case was the girl able to change her own sanitary protection but even in that case she frequently had blood running down her legs at school.

This statement, used as a case-in-point exemplar, also provides a clear indication of possible use of an irreversible clinical procedure to manage what could equally be judged a relatively easy to manage social difficulty.

The concluding section of Appendix A, a 'Brief outline for possible guidelines', includes six recommendations. The expert notes that clear records for diagnosis and indications for surgery should accompany each case of this kind, prior trials of contraceptives should be clearly recorded and prior consultation undertaken with a multidisciplinary committee. In addition, the patient's interests should be considered and recorded, parents'/caregivers' interests should also be considered and recorded, and an independent patient advocate be engaged as part of the process if the interests of the person concerned and the parent/caregiver differ. These recommendations suggest that the clinical specialist involved may have been uneasy about key aspects of the instigation and management of the procedure in some cases, including the role of parents/caregivers in decisions to ask for this procedure, and the lack of standardisation of reporting procedures. Finally, the audit process was made no easier by the complete lack of data in two cases and the significant lack of information in at least three others.

\section{Final J\&ESC report details}

Further documentation related to the final outcome of CCS's submission to the J\&ESC reveals the extent of the impact of the $\mathrm{MOH}$ report on the final recommendation made by the J\&ESC about inclusion of CCS's proposed clause. The paragraph containing the Committee's final recommendation to Parliament is included in full below (emphasis added):

CCS raised the concern that hysterectomy in young women with intellectual disabilities is being 
used for the purposes of non-therapeutic sterilization, and submitted that where there is no medical need for sterilisation or where a child has difficulty in giving informed consent, sterilisation must not occur. We note a Ministry of Health document, dated 20 March 2002 and entitled 'Hysterectomies in young women with intellectual disabilities' reports that the Ministry's clinical view of the indications for hysterectomy in young women with intellectual disabilities confirms that the practice reported by CCS does not appear to be the case. In the report, officials recommend that this should remain an issue of individual clinical judgement, while noting that the Ministry of Health is still exploring the option of improving guidelines for management of hysterectomies for this group. (Care of Children Bill Justice and Electoral Committee 2003, p. 17, emphasis added.)

These comments negated the idea that nontherapeutic sterilisation procedures were being carried out, thus ending the possibility of the inclusion of CCS's proposed safeguard clause in the final COCA. Under COCA, responsibility was placed on medical practitioners in Section 36(1)(b) to be satisfied that the particular procedure sought would be for the young (intellectually disabled) patient's benefit. Parental consent to medical treatment was also provided for in Section 36 (see Shrenk 2011 for more details). ${ }^{3}$ However, these provisos fall short of ensuring in law the necessity CCS saw for independent scrutiny of the rights of the intellectually disabled person concerned in all cases where sterilisation-related procedures are sought.

It is questionable whether Appendix A provided definitive proof that 'the practice reported by CCS does not appear to be the case'. Equally, this information signalled a number of issues that warranted the provision of more information to the J\&ESC and much more discussion within the Committee about this issue as, by 2004, the policy landscape had changed considerably. Comparing the measures included in COCA related to sterilisation with relevant objectives and action points of the NZDS relating to sexuality and relationships reveals a sizable discrepancy between the spirit and intention of these two documents. Objective 9, Action Point 14.4 of NZDS states that government is to ensure that the "criteria and considerations for the health and reproductionrelated treatment for disabled women are the same as for non-disabled women' (Office of Disability Issues 2001, p. 28). In the absence of the definitive safeguard clause proposed by CCS, COCA could not fully ensure that the health and reproductive safety of intellectually disabled girls and women under the age of 18 with severe impairments was anything like the same as enjoyed by their non-disabled peers. In the final part of this paper the following points of discussion are raised as avenues for further consideration in respect of this extremely sensitive issue.

\section{Discussion}

At the end of a substantial investigation the questions that initially prompted this inquiry could not be fully answered. However, the following statement from a page of a New Zealand law firm's website outlining the range of legal expertise held in the firm provides a credible indicator that procedures are still being sought:

Advising a District Health Board on consent issues arising from a proposed sterilization of an intellectually disabled young woman. (BuddleFindlay 2011)

Why are procedures still wanted? How are decisions being made in these cases? Where are procedures being carried out? What part are family members, intellectually disabled people themselves, service agencies and clinicians playing in this process? In their summary of the content of the supplementary submission made to the COCB in 2004, CCS stated that the level of public debate about non-consensual sterilisation and the availability of legal safeguards in this area for young disabled people in New Zealand continued to lag behind similar international jurisdictions (CCS 2004). In 2012 
this point is still valid. In 2007, New Zealand signed the United Nations Convention on the Rights of Disabled People (United Nations 2007). Article 23 of the Convention states that all parties are to 'take effective and appropriate measures to eliminate discrimination against persons with disabilities in all matters relating to marriage, family, parenthood and relationships, on an equal basis with others'. Can New Zealand currently guarantee that all effective and appropriate measures are being taken to eliminate discriminatory practices in relation to sterilisation and young intellectually disabled women and girls - or that measures put into place operate effectively in all cases? Without access to comprehensive incidence and prevalence data, including rounded investigations of reasons for initiating any procedure undertaken in relation to girls and women under the age of 18 , it is not possible to affirm that procedures sought are always actioned solely for therapeutic purposes.

Appendix A provides a significant example of how medical specialists provided with a brief to evaluate clinical conditions are likely to lean towards the adoption of clinical outcomes as a result of their deliberations (Kittay 2011). In this regard, the presence of 'diagnostic overshadowing', where behavioural symptoms displayed by intellectually disabled people are attributed to impairment effects rather than social difficulties, may severely limit the degree to which medical practitioners are able to explore solutions that lie beyond clinical frameworks (Ouellette 2008). While the clinical expert in Appendix A was clear that the primary causal factor for sterilisation in 11 of the 14 cases was management of 'pathological uterine bleeding', she herself was not absolutely certain about the clinical validity of this reason in the final three cases under review. Nor was she able to clinically assess the two missing cases. Establishing a workable consensus in the medical community as a whole about when and if sterilisation might be warranted, and how the procedure is to be recorded, would go some way to addressing this point, but using clinical solutions to address the problem of inadequate societal support for vulnerable young intellectually disabled people does not solve the issue. While current provision in relation to legal oversight of sterilisation requests for intellectually disabled women age 18 and over is robust, the same cannot be said of provision for those under the age of 18 . Greater measures designed to safeguard bodily integrity and to bring a greater degree of transparency to this process for people in his age group are needed. Yet where might it be best to develop these conversations? Legislating for the inclusion of an independent person within the oversight framework might provide a useful way forward in individual cases, as CCS indicated in their supplementary submission (CCS 2004). CCS further proposed that this person should have a thorough knowledge of disability issues and rights, and also expertise in the lived experience of disability. However, these suggestions do not displace a fundamental concern that remains about how this issue is currently conceptualised and reconciled.

Ensuring that disabled children and young people have the same rights as non-disabled, with additional rights to support in areas according to need, should be a social obligation that is now well embedded in our policies and practices. Yet a significant example of terminology slippage noted in Appendix A presents a challenge to the efficacy of 'individual rights' discourses to successfully counter still-prevalent social norms that lie deeply imbedded in the final decision to sterilise in at least some of the cases the clinician examined. The clinical notes that comprise Appendix A show how key descriptors shifted register, during the investigative procedure, from the biomedical-'menorrhagia or dysfunctional uterine bleeding'on page 1 to the socio-cultural-'blood running down her legs at school'-on page 2. The very distressing past history of use of sterilisation procedures and intellectually disabled people may still affect our degree of comfort in relation to how this issue is discussed in the twenty-first century. However, unless we as a 
community can move past the feelings of shame and disgust that continue to surround key functions of the female body, rights claims may not bring enough pressure to bear to prevent medical procedures being deployed to modify the person rather than the custom. Wider societal conversations are needed to counter suggestions that sterilisation-related procedures provide a 'valid therapeutic response' to menstrual management for disabled girls and women. These conversations will also need to include how the lack of consideration and respect currently given to menstruation as a healthy and biologically vital process is to be overcome (Gomez 2011). Notwithstanding, it is notable that information about the sterilisation of intellectually disabled boys and men in this country has been virtually impossible to find. The only figures located during the course of this investigation include an early record of two bilateral orchidectomy operations and one vasectomy on young men age aged between 15-20 years (Gates 2000). Following Keywood (2001), these operations may have been undertaken in relation to future sexual encounters that have might end in pregnancy for the women involved. Given that it is not necessary for practitioners to report procedures performed in outpatient settings, possible numbers of sterilisations performed on men and boys remains completely hidden. More research in this area is needed.

\section{Notes}

1. All material related to the submissions made to this J\&ESC is held as hard copy, thus only available on application to The Librarian, The General Assembly Library, Parliament Buildings, Wellington, New Zealand. Access from: http:// www.panoramicearth.com/2334/Wellington/General_Assembly_Library

2. $\overline{\mathrm{CCS}}$ and $\mathrm{IHC}$ are non-government agencies funded to provide support and advocacy services to disabled and intellectually disabled people in New Zealand.

3. Details of the two judgments involved $-\mathrm{Re} H$ and Re X - can be found in Shrenk (2011). Both judgments were given prior to adoption of COCA 2004.

\section{References}

Alvares A, Case H, Kronenberger E, Ortoleva S, Tosti-Vasey J 2011. Reproductive health justice for women with disabilities. http://www.centerwomenpolicy.org/ (accessed 22 August 2011).

Bersanti H 2008. If 'growth attenuation' is the answer... what is the question? Paper presented at the 13th World Congress of the International Association for the Scientific Study of Intellectual Disabilities, 26 August 2008, Capetown, South Africa. http://www.wou.edu? bersanh (accessed 22 August 2011).

Buddle-Findlay 2001. Advising a District Health Board on consent issues arising from a proposed sterilization of an intellectually disabled young woman. http://www.buddlefindlay.com/our-expertise/secondary-expertise/mental-health-andintellectual-disability (accessed 22 August 2011).

Care of Children Bill Justice and Electoral Committee 2003. Reports of Committees. http://www.parlia ment.nz/enNZ/PB/SC/Documents/Reports/5/1/ a8868970934ac684f74fc3ec3bald3.htm (accessed 22 August 2011).

CCS 2003. Submission to the Justice and Electoral Select Committee on the Care of Children Bill. Unpublished manuscript.

CCS 2004. Supplementary submission on Care of Children Bill. Unpublished manuscript.

Chu Y-C, Lu Z-H 2011. Deciding about sterilisation: perspectives from women with an intellectual disability and their families in Taiwan. Journal of Intellectual Disability Research 55: 63-74.

Gates S 2000. A human wrong? Sterilization of young girls and women with intellectual disabilities in New Zealand. Unpublished manuscript.

Gomez J 2011. Disability and menstruation... the not-so-white (in fact red) elephant in the room. E-bulletin (Winter). http://www.wchm.org.au/ E-bulletin-Winter-2011\#Disability\%20\%20Me nstruation (accessed 22 August 2011).

Hamilton C 2011. Community member's responses to the elective hysterectomy of an intellectually disabled girl. Journal of Social Inclusion 2: 24-38.

Keywood K 2001. I'd rather keep him chaste. Retelling the story of sterilization, learning disability and (non)sexed embodiment. Feminist Legal Studies 9: 185-194.

Kittay E 2011. Forever small: the strange case of Ashley X. Hypatia 26: 610-630.

Living Archives 2010. Eugenics in Western Canada. Eugenics Archives. http://eugenicsarchive.ca/ (accessed 22 August 2011). 
Malacrida C 2006. Contested memories: efforts of the powerful to silence former inmates' histories of life in an institution for mental defectives. Disability and Society 21: 397-410.

Ministry of Health (MOH) (2002). Hysterectomies in young women with intellectual disabilities. Report HC85-16-2. Wellington, New Zealand, $\mathrm{MOH}$.

Office of Disability Issues 2001. New Zealand Disability Strategy. http://www.odi.govt.nz/nzds (accessed 22 August 2011).

O'Neil N 1996. Sterilisation of children with intellectual disabilities. Australian Journal of Human Rights 2(2). http://www.austlii.edu.au/ au/journals/AUJlHRights/1996/8.html (accessed 22 August 2011).

Ouellette AR 2008. Growth attenuation, parental choice and the rights of disabled children: lessons from the Ashley $\mathrm{X}$ case. Houston Journal of Health, Law \& Policy 8: 207-244.

Report of the Confidential Forum for Former InPatients of Psychiatric Hospitals 2007. Te Aiotanga. http://www.platform.org.nz/page/ platform_142.php (accessed 22 August 2011).

Roets G, Adams M, Van Hove G 2006. Challenging the monologue about silent sterilisation: implications for self-advocacy. British Journal of Learning Disability 34: 167-174.

Shrenk A 2011. New Zealand law on the sterilisation of intellectually disabled girls and women. Health Research Council Ethics Summer Studentship Report. www.hrc.govt.nz/news-and-media/news/ ethics-summer-studentships (accessed 22 August 2011).
Snyder S, Mitchell D 2001. A world without bodies. Brace Yourself Productions. [Motion picture]. New York, Program Development Associates.

Stace H 2008. Gene dreaming: New Zealanders and eugenics. Professional Historians Association of New Zealand. http://www.phanza.org.nz/ content/gene-dreaming-new-zealanders-and-eugenics (accessed 22 August 2011).

Stace H, Sullivan M 2011. A society that highly values our lives and continually enhances our full participation. Policy Quarterly 7: 50-55.

Stansfield A, Holland A, Claire I 2007. The sterilization of people with intellectual disabilities in England and Wales during the period 1988 to 1999. Journal of Intellectual Disability Research 15: 569-579.

Sullivan M 1995. Regulating the anomalous body in Aotearoa/New Zealand. New Zealand Journal of Disability Studies 1: 9-29.

Thomas C 1997. The intellectually disabled and sterilisation: can the health and disability prove sufficient protection of rights? Butterworth Family Law Journal (March): 108-112.

Tilley E, Walmsley J, Earle S, Atkinson D 2012. The silence is roaring: sterilization, reproductive rights and women with intellectual disabilities. Disability and Society 27: 413-426.

United Nations 2007. United Nations Convention on the Rights of Persons with Disabilities. http://www.un.org/disabilities/convention/conventionfull.shtml (accessed 22 August 2011).

Wicks W 2003. Re: CCS supplementary submission on Care of Children Bill [Letter to the Committee Chair Tim Barnett]. Unpublished manuscript. 